\title{
Het ritme van de tijdsbesteding van de PGO-student
}

\author{
M.W.M. Jongbloets, D.H.J.M. Dolmans, R.J.I. Hoogenboom, H.A.P. Wolfhagen
}

\begin{abstract}
Samenvatting
Door middel van een tidschrifonderzok (logboek) is informate verzameld over de studeactiviteiten van geneskundestudenten in het vierde blok van het eerste studiejar te Mastricht Ondertocht is hoveel van de ingeroosterde activiten studenten daadwerkelik volgen en hoevel tija studenten besteden adn ingeroosterde en telfstideactiviteiten. Daanast is nagegan hoe de verhouding is tussen de tid besteed aan ingeroosterde activiteiten en de tid besteed an zelfstide. Tenslotte is bekeken hoe stidenten de telfstietid verdelen over een blokperiode van tes weken. Jit de resultaten blikt dat de studenten consequent deelnemen an de meeste ingeroosterde activiteiten. Ze besteden in het onderochte blok gemideld 23 ur per week ad hun stude. Gemiddeld genomen word de helf van de totale studietid besteed an zelfstide en de helft an ingeroosterde activiteiten. Het studiegedrag gedurende het blok is regelmatg, zij het dat in de laatste week van het blok meer tid bested word adn zelfstdie dan aan ingeroosterde activiteiten.
\end{abstract}

\section{Inleiding}

Probleemgestuurd onderwijs (PGO) is een vorm van studentgecentreerd onderwijs. In PGO ligt een sterke nadruk op actief leren. Een studentgecentreerd curriculum wordt gekenmerkt doordat er, naast de tijd voor ingeroosterde (veelal docentafhankelijk) activiteiten, veel tijd is ingeruimd voor zelfstudie. ${ }^{1}$ Dit om te bevorderen dat studenten actief met de leerstof bezig zijn. De zelfstudie is bedoeld om de leerstof te verwerken die aan bod is geweest tijdens verschillende ingeroosterde activiteiten, zoals lezingen, onderwijsgroepsbijeenkomsten en practica.

Het Maastrichtse geneeskundeonderwijs in de eerste vier studiejaren is probleemgestuurd en studenten krijgen veel ruimte voor zelfstudie om de verschillende onderwijsactiviteiten voor te bereiden. Het studiejaar is verdeeld in blokperiodes van zes weken. De kern van de verschillende studieactiviteiten in een blok wordt gevormd door de bijeenkomsten van de onderwijsgroepen van acht tot tien studenten.
Daarnaast kunnen de studenten onder andere lezingen, practica en vaardigheidstrainingen volgen. Alleen voor de onderwijsgroepen geldt een aanwezigheidsplicht, de andere onderwijsactiviteiten zijn facultatief. Bij het vormgeven van het programma is in principe rekening gehouden met bevindingen uit een onderzoek van Vos naar de tijd besteed aan zelfstudie en het aantal ingeroosterde uren. Uit de resultaten van dit onderzoek kwam naar voren dat studenten meer tijd besteden aan zelfstudie naarmate het aantal ingeroosterde uren stijgt. Echter, er is een punt waarop de aan zelfstudie bestede tijd afneemt als het aantal ingeroosterde uren verder stijgt. Van een optimale situatie is sprake indien 30 tot $40 \%$ van de tijd gepland wordt voor ingeroosterde onderwijsactiviteiten en 60 tot $70 \%$ voor zelfstudie, bij een gemiddelde netto tijd voor ingeroosterde onderwijsactiviteiten van tussen 9 en 11 uur per week. De maximaal te realiseren gemiddelde inspanning is 31 uur per week. Dat wil zeggen dat de maximaal te behalen zelfstudietijd bij 
een onderwijsdeelname van tussen de 9 en 11 uur per week, gemiddeld 20 à 22 uur per week is. ${ }^{2}$ Van den Hurk et al. hebben voor de Maastrichtse geneeskundestudie nagegaan hoeveel uren gemiddeld per week ingeroosterd zijn en ze hebben studenten gevraagd globaal te schatten hoeveel uren ze per week aan zelfstudie besteden. ${ }^{3}$ Uit dit onderzoek bleek dat de verdeling zelfstudietijd/ingeroosterde tijd in Maastricht ongeveer overeenkomt met het model van Vos. Hoewel het onderzoek van Van den Hurk et al. inzicht biedt in de verhouding tussen ingeroosterde tijd en zelfstudietijd, blijft een aantal vragen onbeantwoord. Zo is niet onderzocht hoeveel ingeroosterde activiteiten studenten daadwerkelijk volgen. Een andere vraag is of de resultaten veranderen als de studenten tijdschrijven in plaats van tijd globaal schatten. Onbekend is ook wanneer studenten tijd aan zelfstudie besteden. Behalve dat in PGO veel tijd voor zelfstudie is ingeruimd, lokt PGO ook regelmatig zelfstudiegedrag uit. Een onderwijsgroep komt tweemaal per week bijeen. Tijdens de eerste onderwijsgroepsbijeenkomst in een blokweek bespreken studenten een onderwerp voor en formuleren ze vragen die bestudeerd moeten worden. $\mathrm{Na}$ twee dagen rapporteren ze aan elkaar de bevindingen in de vorm van een discussie. Een student die onvoorbereid naar de onderwijsgroep gaat, kan nauwelijks deelnemen aan de discussie. Zelfstudie is niet alleen nodig als voorbereiding op de onderwijsgroepen. Practica en trainingen vragen ook voorbereiding. De vraag is echter of dit in de praktijk zo werkt. Met andere woorden, verdelen studenten hun zelfstudieactiviteiten regelmatig over de blokperiode. Om de hierboven beschreven vragen te beantwoorden zijn drie onderzoeksvragen geformuleerd:

1. Hoeveel procent van de ingeroosterde activiteiten volgen studenten daadwerkelijk?
2. Hoeveel tijd besteden studenten aan de verschillende ingeroosterde activiteiten en aan zelfstudieactiviteiten en hoe is de onderlinge verhouding?

3. Hoe is de zelfstudietijd verdeeld over een blokperiode van zes weken?

\section{Methode}

\section{Proefpersonen}

Het onderzoek is uitgevoerd gedurende het vierde blok in het eerste jaar van het Maastrichtse geneeskundecurriculum. Dit blok is getiteld Aanval en Afweer en beslaat zes weken. Voor elke blokperiode worden studenten at random ingedeeld in onderwijsgroepen. Voor dit onderzoek zijn uit elke onderwijsgroep at random drie à vier studenten schriftelijk benaderd met de vraag of ze mee wilden werken aan een tijdschrijfonderzoek. Van de 87 benaderde studenten (44\% van de eerstejaars studenten) hebben 61 studenten het logboek ingevuld. De respons bedroeg dus $70 \%$.

\section{Instrument}

De studenten ontvingen aan het begin van het blok een logboek waarin ze konden invullen hoeveel tijd ze besteed hadden aan de verschillende studieactiviteiten in het blok. De verschillende activiteiten worden nu eerst kort toegelicht.

1. Onderwijsgroep: Gedurende de blokperiode vinden elke week twee bijeenkomsten plaats van twee uur.

2. Lezingen: Deze worden door docenten gegeven om bepaalde onderwerpen van het betreffende blok nader te verduidelijken.

3. Skillslabtraining: Tijdens deze trainingen leren studenten vaardigheden met betrekking tot medisch-technische handelingen.

4. Practica: Tijdens de practica worden bepaalde onderwerpen, zoals anatomie, 
fysiologie en het omgaan met apparatuur, nader uitgediept.

5. Medisch Praktisch Onderwijs: Dit onderwijs vindt twee keer per blok plaats en duurt twee uur per bijeenkomst. In kleine groepen (tien studenten) komen communicatievaardigheden, attitudeontwikkeling en omgaan met patiënten aan de orde. Ook worden praktijkcontacten nabesproken.

6. Praktijkcontacten: Er zijn verschillende kortdurende praktijkcontacten in verschillende disciplines van de gezondheidszorg.

7. Kopiëren: De studenten kunnen de literatuur die zij nodig hebben voor de zelfstudie, in de universiteitsbibliotheek kopiëren.
8. Bloktoets: Na ieder blok wordt een bloktoets afgenomen over de inhoud van het blok.

9. Vaardigheidstoets: De vaardigheidstoets wordt aan het einde van elk studiejaar afgenomen om de vaardigheden van studenten te meten.

10. Voortgangstoets: De voortgangstoets wordt viermaal per jaar afgenomen. Middels deze toets worden de vorderingen van de studenten getoetst door vragen te stellen met betrekking tot de leerstof van alle studiejaren.

Voorafgaand aan het onderzoek is het logboek voor commentaar voorgelegd aan enkele studenten. Bovendien is aan acht studenten gevraagd het concept-logboek

Figuur 1. Het schema uit het logboek dat door studenten dagelijks is ingevuld.

\begin{tabular}{|c|c|c|}
\hline Activiteiten & Zelfstudie & Deelname \\
\hline Onderwijsgroep & ... uur en ... kwartier & ... uur en ... kwartier \\
\hline Lezing & ... uur en ... kwartier & ... uur en ... kwartier \\
\hline Skillslabtraining & ... uur en ... kwartier & ... uur en ... kwartier \\
\hline Practicum & ... uur en ... kwartier & ... uur en ... kwartier \\
\hline MPO-onderwijs & ... uur en ... kwartier & ... uur en ... kwartier \\
\hline Praktijkcontacten & ... uur en ... kwartier & ... uur en ... kwartier \\
\hline Kopiëren & ... uur en ... kwartier & ... uur en ... kwartier \\
\hline Bloktoets & ... uur en ... kwartier & ... uur en ... kwartier \\
\hline Vaardigheidstoets & ... uur en ... kwartier & ... uur en ... kwartier \\
\hline Voortgangstoets & ... uur en ... kwartier & ... uur en ... kwartier \\
\hline Overige activiteiten & ... uur en ... kwartier & ... uur en ... kwartier \\
\hline Totaal & ... uur en ... kwartier & ... uur en ... kwartier \\
\hline
\end{tabular}


gedurende een week in te vullen. Naar aanleiding hiervan zijn nog enkele marginale verbeteringen aangebracht. Uit dit vooronderzoek bleek dat het invullen van het logboek ongeveer vijf minuten per dag in beslag nam. Het schema dat de studenten elke dag invulden, is weergegeven in figuur 1. De studenten werd gevraagd om per dag in te vullen hoeveel uur zij besteed hadden aan ingeroosterde activiteiten en hoeveel uur zij voor deze activiteit aan zelfstudie hadden besteed. Het logboek diende gedurende de totale duur van het blok (dus zes weken) ingevuld te worden. Studenten werd gevraagd de bestede tijd tot op het kwartier nauwkeurig aan te geven. Studenten die het logboek gedurende zes weken invulden, ontvingen hiervoor een waardebon.

\section{Analyses}

Alle gegevens zijn eerst geanalyseerd op studentniveau en vervolgens op groepsniveau. Voor alle activiteiten is de tijdsbesteding berekend per dag, per week en voor de hele periode. Hierbij is zoveel mogelijk gebruik gemaakt van de mediane waarde, omdat deze een betere schatting geeft van de feitelijke gegevens indien er sprake is van een grote spreiding.

\section{Resultaten}

De resultaten zullen per onderzoeksvraag besproken worden. Eerst dient nog vermeld te worden dat dit blok feitelijk een periode van zeven weken in beslag nam, omdat één week voor vakantie gereserveerd was. In deze vakantieweek waren er geen activiteiten ingeroosterd. Bij de verwerking van de gegevens bleek dat een aantal studenten in deze vakantieweek toch enkele uren aan zelfstudie had besteed, namelijk zes uur. Deze week is bij een aantal analyses niet betrokken.

\section{Onderzoeksvraag 1: Hoeveel procent van de ingeroosterde activiteiten volgen studenten daadwerkelijk?}

Het aantal ingeroosterde onderwijsactiviteiten in dit blok bedraagt voor de gehele periode van zes weken 75 uur. Uit de resultaten blijkt dat de studenten feitelijk 66 uur (11 uur per week) (mediane waarde) besteden aan ingeroosterde activiteiten. Kortom: $88 \%$ van de ingeroosterde onderwijsactiviteiten wordt daadwerkelijk benut.

\section{Onderzoeksvraag 2: Hoeveel tijd besteden studenten aan de verschillende ingerooster- de activiteiten en aan zelfstudieactiviteiten en hoe is de onderlinge verhouding?}

De studenten die deelnamen aan dit onderzoek, zijn gemiddeld 23 uur per week (mediane waarde) met hun studie bezig (exclusief de zelfstudie-uren in de vakantieweek). Wanneer dit wordt opgesplitst in uren besteed aan zelfstudie en ingeroosterde activiteiten, dan wordt aan beide gemiddeld 11 uur per week besteed (mediane waarde en exclusief vakantieweek). Aangezien het mediane waarden betreft is de som van de zelfstudie-uren en de uren deelname aan ingeroosterde activiteiten niet gelijk aan het totale aantal uren besteed aan de studie per week.

Een andere analyse van de zelfstudietijd, waarbij gekeken is naar de tijdsbesteding over de totale periode van zes weken, laat zien dat aan de voorbereiding voor de onderwijsgroepen gemiddeld 47 uur wordt besteed, aan de bloktoets gemiddeld 21 uur en aan de voorbereiding voor praktijkcontacten gemiddeld 5 uur. Het blijkt dat er niet veel tijd wordt besteed aan het voorbereiden van andere activiteiten. Opmerkelijk is dat er weinig voorbereidingstijd besteed wordt aan skillslabtrainingen en practica. Verder geldt voor de deelname aan ingeroosterde activiteiten dat de meeste tijd besteed wordt aan 
de onderwijsgroepen en de practica, respectievelijk 17 en 16 uur. Ook wordt er redelijk veel tijd besteed aan lezingen en praktijkcontacten, beide 10 uur. Aan skillslabtrainingen en Medisch Praktisch Onderwijs wordt elk 7 uur besteed (tabel 1).

\section{Onderzoeksvraag 3: Hoe is de zelfstudietijd verdeeld over een blokperiode van zes weken?}

In week 1 tot en met 5 is er sprake van enige regelmaat. Het aantal uren dat de studenten aan hun studie besteed hebben in deze weken varieert van 22 tot 24 (mediane waarden). Opsplitsing hiervan laat zien dat het aantal uren besteed aan zelfstudie en het aantal uren besteed aan de onderwijsactiviteiten niet wezenlijk van elkaar verschillen. De tijd die studenten besteden aan zelfstudie varieert van 8 tot 11 uur per week. Aan ingeroosterde activiteiten besteden studenten 11 tot 12 uur. In week 6 (vakantieweek) zijn deze aantallen vanzelfsprekend lager, er waren immers geen onderwijsactiviteiten in deze week, en de zelfstudie bedroeg gemiddeld 6 uur. Opvallend is dat deelname in de laatste week van het blok afneemt tot 9 uur, terwijl de tijd voor zelfstudie toeneemt tot 18 uur. Dit brengt het totaal aantal uren dat in deze week aan de studie wordt besteed op 27 uur. Dit is beduidend meer dan het aantal uren dat in de eerste weken aan de studie besteed wordt (tabel 2).

\section{Beschouwing}

Hoewel de hoeveelheid (zelf)studietijd per student nogal blijkt te verschillen, geeft dit onderzoek een indicatie van de wijze waarop studenten in het Maastrichtse PGO-curriculum met hun tijd omgaan en dus ook van de studeerbaarheid van het programma. Studenten blijken ongeveer $88 \%$ van de ingeroosterde activiteiten bij

Tabel 1. Gemiddeld aantal uren dat studenten gedurende het blok besteden aan zelfstudie en deelname aan ingeroosterde activiteiten (rekenkundig gemiddelde).

\begin{tabular}{lcc}
\hline Activiteiten & $\begin{array}{c}\text { Onderwijsdeelname } \\
\text { Gemiddeld aantal uren }\end{array}$ & $\begin{array}{c}\text { Voorbereidende zelfstudie } \\
\text { Gemiddeld aantal uren }\end{array}$ \\
\hline Onderwijsgroep & 17 & 47 \\
Lezingen & 10 & 1 \\
Skillslabtrainingen & 7 & 2 \\
Practica & 16 & 3 \\
Medisch Praktisch Onderwijs & 7 & 2 \\
Praktijkcontacten & 10 & 5 \\
Kopiëren & - & 4 \\
Bloktoets & 2 & 21 \\
Vaardigheidstoets & 0 & 0 \\
Voortgangstoets & 0 & 0 \\
Overige activiteiten & 1 & 1 \\
& & $84^{*}$ \\
Totaal & $68^{*}$ &
\end{tabular}

* Omdat de getallen afgerond zijn, is de som van de tijd voor zelfstudie en de som van de tijd voor deelname niet gelijk aan het totaal aantal uren. 
Tabel 2. Aantal uren dat studenten per week besteden aan de studie, opgesplitst in zelfstudie en deelname aan ingeroosterde activiteiten (mediane waarde).

\begin{tabular}{lccc}
\hline Weeknummer & Totaal $^{*}$ & Zelfstudie & Deelname \\
\hline Week 1 & 22 & 10 & 11 \\
Week 2 & 24 & 11 & 11 \\
Week 3 & 23 & 11 & 12 \\
Week 4 & 23 & 11 & 11 \\
Week 5 & 22 & 8 & 12 \\
Week 6 (vakantie) & 6 & 6 & - \\
Week 7 & 27 & 18 & 9 \\
& & & 11 \\
Totaal $^{* *}$ & 23 & 11 & \\
\hline
\end{tabular}

* Omdat mediane waarden vermeld zijn in de tabel is de som van de tijd voor zelfstudie en deelname niet altijd gelijk aan het totaal.

** De getallen in deze rij zijn exclusief week 6 .

te wonen. Aangezien een groot deel van de onderwijsactiviteiten niet verplicht is, kan dit percentage als bevredigend gezien worden. Opgemerkt dient te worden dat aanwezigheid niets zegt over de mate waarin een student actief participeert. Niettemin werd in een onderzoek van Scherpbier et al. aan de Faculteit Geneeskunde in Maastricht een positief verband gevonden tussen toetsresultaten en de aanwezigheid bij vaardigheidstrainingen en anatomiepractica. ${ }^{4}$

Studenten hebben in het onderzochte blok netto 23 uur per week (mediane waarde, exclusief week 6) aan hun studie besteed. Aan de diverse activiteiten worden verschillende hoeveelheden tijd besteed. Gemiddeld genomen wordt hiervan de helft besteed aan zelfstudie en de helft aan ingeroosterde activiteiten. Aan het voorbereiden van skillslabtrainingen en practica wordt weinig tijd besteed. Geconcludeerd kan worden dat er vooral in week 1 tot en met 5 regelmatig gestu- deerd wordt, zowel wat betreft uren zelfstudie als deelname aan de verschillende onderwijsactiviteiten. In de laatste week van het blok neemt de deelname aan de activiteiten iets af, terwijl de zelfstudie iets toeneemt; een tendens die te verwachten valt vlak voor een bloktoets. In deze laatste week wordt meer tijd besteed aan het voorbereiden voor de bloktoets.

Wanneer deze gegevens gerelateerd worden aan de resultaten van het onderzoek van Vos, dan kan geconcludeerd worden dat de verhouding zelfstudietijd versus ingeroosterde tijd in het blok redelijk overeenkomt met de situatie die volgens het onderzoek van Vos optimaal is. In het blok wordt $45 \%$ van de studietijd besteed aan ingeroosterde activiteiten (optimale situatie volgens Vos: $30-40 \%$ ) en 50\% aan zelfstudie (optimale situatie volgens Vos: 60-70\%). Wat betreft studiebelasting lijkt het blok dan ook studeerbaar. Verder blijkt dat de gemiddelde netto tijd voor inge- 
roosterde activiteiten rond de 11 uur per week ligt. Dit komt overeen met het ideale aantal van tussen 9 en 11 uur per week. De zelfstudietijd in dit onderzoek bedraagt 11 uur per week en ligt dus aanzienlijk lager dan de volgens het onderzoek van Vos maximaal te behalen zelfstudietijd van 20 à 22 uur. $^{2}$ Verder blijkt in dit onderzoek dat de totale studietijd 23 uur per week bedraagt. Dit ligt dus ook aanzienlijk lager dan de maximaal te realiseren 31 uur volgens het onderzoek van Vos. Er wordt dus zowel aan zelfstudie als aan alle studieactiviteiten samen minder tijd besteed dan op grond van de onderzoeksresultaten van Vos te verwachten zou zijn. Een mogelijke verklaring voor deze discrepantie is dat het onderzoek van Vos uitgevoerd werd in 1985 en dat studenten destijds waarschijnlijk minder tijd besteedden aan werken naast de studie.

Als onderdeel van de reguliere programma-evaluatie aan het einde van elk blok dienen studenten volgens de globale schattingsmethode aan te geven wat de gemiddelde studielast per week is in het betreffende blok en hoeveel uren hiervan aan zelfstudie besteed worden. ${ }^{5}$ Uit die reguliere gegevens blijkt dat de studenten in het onderzochte blok 25 uur aan de studie besteden, waarvan 12 uur per week aan zelfstudie (mediane waarden). Voorts blijkt uit de reguliere programma-evaluatie dat de studenten aan $88 \%$ van de ingeroosterde activiteiten deelnemen. Dit komt dus nagenoeg overeen met de in dit onderzoek gevonden waarden. Hieruit kan geconcludeerd worden dat de gegevens van de globale tijdschrijfmethode en de analytische methode met elkaar overeenkomen. Wat dat betreft is de globale schattingsmethode, die in de reguliere programma-evaluatie gebruikt wordt, een relatief eenvoudige en makkelijke manier om inzicht te krijgen in de studiebelasting van studenten. Kortom: tijdschrijven geeft geen ander beeld dan tijdschatten. De bevinding dat de globale schattingsmethode en de tijdschrijfmethode nagenoeg dezelfde resultaten opleveren, is ook gerapporteerd door Pöll-Tjepkema en Van den Haak, die een vergelijkbaar onderzoek deden bij een opleiding voeding en diëtetiek. ${ }^{6}$ Om inzicht te krijgen in het aantal uren dat studenten besteden aan hun studie kan dan ook volstaan worden met de globale schattingsmethode. Is echter inzicht nodig in de verdeling van de tijd over een periode, dan is het nodig studenten gedetailleerder te laten tijdschrijven.

\section{Literatuur}

1. Wijnen WHFW, Wolfhagen HAP, Bie D de, Brouwer OG, Ruijter CTA, Vos P. 'Te doen of niet te doen?' Advies over de studeerbaarheid van onderwijsprogramma's in het hoger onderwijs. Leiderdorp: Graficon; 1992.

2. Vos P. Zelfstudie als functie van onderwijsdeelname: hypothesetoetsing. Tijdschrift voor Onderwijsresearch 1985;10(5):228-38.

3. Hurk MM van den, Wolfhagen HAP, Dolmans DHJM, Vleuten CPM van der. Een inventarisatie van de studielast in het preklinisch curriculum geneeskunde. In: Cate ThJ ten, Dikkers JH, Houtkoop E, Pollemans MC, Pols J, Smal JA, redactie. Gezond Onderwijs-5. Houten: Bohn Stafleu Van Loghum; 1995. p. 183-9.

4. Scherpbier AJJA, Verhoeven BH, Mameren H, Kerkhofs E, Hoogenboom RJI, Vleuten CPM van der. Aanwezigheid en toetsprestaties: een exploratieve studie. Bulletin Medisch Onderwijs 1999;18:17-28.

5. Dolmans DHJM, Wolfhagen HAP, Vleuten CPM van der, Schmidt HG. Programme evaluation in pre-clinical years at the Maastricht Medical School. In: Majoor GD, Vleuten CPM van der, Vluggen PMJ, Hansen PA, redactie. Initiatives for change in medical education in Europe for the 21st century. Amsterdam: Thesis; 1997. p. 219-27.

6. Pöll-Tjepkema CPE, Haak E. Schatting van de studielast in een opleiding voeding en diëtetiek. In: Pols J, Cate ThJ ten, Houtkoop E, Pollemans MC, Smal JA, redactie. Gezond Onderwijs-4. Houten: Bohn Stafleu Van Loghum; 1995. p. 176-82. 
De auteurs

M. W.M. Jongbloets is als student-assistent verbonden adn de capaciteitsgroep Onderwijontwikkeling en Onderwisresedroh, Faculteit der Geneskunde, Universiteit Mastricht.

Dr. H.A.P. Wol hagen on ar. D.H.J.M. Domans zin als onderwiskundigen verbonden an de capaciteisgroep Onderwisontwikeling on Onderwisresearch, Faculteit der Geneskunde, Universiteit Madsticht.
R.J.I. Hoogenboom is als onderzoksassistent verbonden aan de capaciteits groep onderwijsontwikkeling en onderwijsesearch, Faculteit der Geneskunde, Universiteit Maastricht.

Correspondentieadres:

D. Dolmans, Capgroep onderwijsontwikkeling en Research, Universiteit Maastricht, Postbus 616, 6200 MD Mastricht

\section{Summary}

Firstyear medical students of Waasticht Medical School were asked to record in a log book the amount of time they spent attending regular curricular activities (lectures, thtorial groups, practicals et ceteral and the time they used for self-directed leaming during a sixweek block period. We wanted to determine the ratio of time spent on regular coursework and that devoted to self-directed learning and also how self-directed learning is distributed over the block period. We found that students atend most of the course activities that are offered on average they study 23 hours per week during the block period, with one half of the time being devoted to regular coursework and the other half to self-directed learning. The amount of time students use for both curricular activites and self-directed learning was distributed rather evenly over the block period, abeit that students devoted more time to self directed learning than to regular coursework during the final week of the block period. Jongbloets MWM, Dolmans DHJM, Hoogenboom RII, Wolfhagen HAP How do PBL-shdents divide their time between regular coursework and self-directed learning. Dutch Joumal of Medical Education 2000; 9 (2):49-56) 